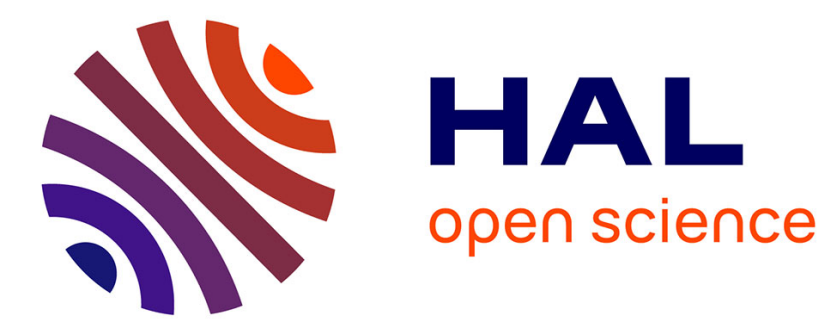

\title{
The Price of Free Advice
}

Machiel van Dijk, Michiel Bijlsma, Marc Pomp

\section{To cite this version:}

Machiel van Dijk, Michiel Bijlsma, Marc Pomp. The Price of Free Advice. Applied Economics, 2008, 40 (14), pp.1889-1903. 10.1080/00036840600905274 . hal-00582063

\section{HAL Id: hal-00582063 https://hal.science/hal-00582063}

Submitted on 1 Apr 2011

HAL is a multi-disciplinary open access archive for the deposit and dissemination of scientific research documents, whether they are published or not. The documents may come from teaching and research institutions in France or abroad, or from public or private research centers.
L'archive ouverte pluridisciplinaire HAL, est destinée au dépôt et à la diffusion de documents scientifiques de niveau recherche, publiés ou non, émanant des établissements d'enseignement et de recherche français ou étrangers, des laboratoires publics ou privés. 


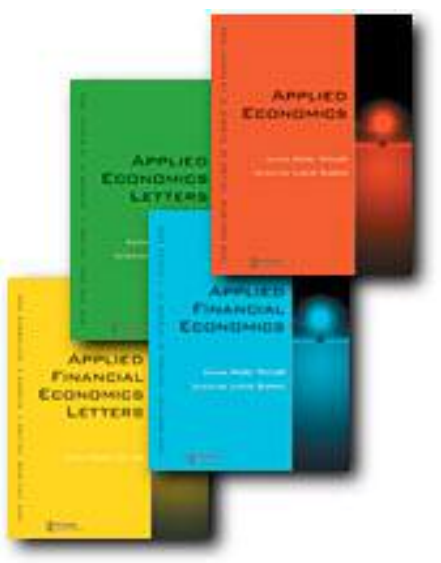

The Price of Free Advice

\begin{tabular}{|r|l|}
\hline Journal: & Applied Economics \\
\hline Manuscript ID: & APE-06-0057.R1 \\
\hline Journal Selection: & Applied Economics \\
\hline JEL Code: & $\begin{array}{l}\text { D12 - Consumer Economics: Empirical Analysis < D1 - Household } \\
\text { Behavior and Family Economics < D - Microeconomics, L84 - } \\
\text { Services < L - Industrial Organization, G22 - Insurance|Insurance } \\
\text { Companies < G2 - Financial Institutions and Services < G - } \\
\text { Financial Economics }\end{array}$ \\
\hline Keywords: & Financial advice, Life insurances, Choice behaviour \\
\hline
\end{tabular}

\section{Manuscript Central ${ }^{\mathrm{m}}$}




\title{
The price of free advice
}

\author{
Machiel van Dijk ${ }^{\star}$ \\ Michiel Bijlsma \\ Marc Pomp
}

CPB Netherlands Bureau for

Economic Policy Analysis

P.O. Box 80510

2508 GM The Hague

The Netherlands

\begin{abstract}
What factors determine how well consumers make their actual choices with regard to financial products? This paper empirically evaluates two different choices consumers make when buying deferred annuities. One choice concerns the type of insurance policy, the other concerns the choice of insurance provider. For both choices we will analyse what factors explain the quality of the choice made. In particular, we will investigate the role of financial advice in the decision making process. By combining Dutch consumer survey data and data on quotations by Dutch life insurance companies, we obtain the following results. First, respondents who buy their policy directly from an insurer attain a significantly better match between their risk preferences and the type of policy chosen than respondents who purchase their policy through an insurance broker. Second, respondents who buy their policy through an insurance broker obtain a significantly lower pay-out than respondents who purchased their policy directly from an insurance company. These results raise doubts about the functioning of both the market for financial advice and the market for life insurances.
\end{abstract}

* Corresponding author; e-mail: mfvd@cpb.nl 


\section{Introduction}

A well functioning retail market for financial products requires, inter alia, that consumers can find the product that matches their preferences at the lowest possible price. Financial products, and in particular life insurance products, are generally considered to be complex. Searching and comparing financial products can therefore be difficult and time consuming. For this reason, many people rely on financial advisors to help them choose the right products. However, the market for financial advice may not function properly. In particular, due to the incentive structure in his market (commissions paid by insurers) coupled with the infrequent purchase of these products and the lack of sufficient expertise by consumers, financial advise may be biased This bias may take several forms. First, if advisors earn more on certain types of products than on other types of products, this may give rise to biased choice of product type. Second, if advisors earn more on products from firm A than on products from firm B (within a given type of product), then this may lead to a bias in the firm choice. Both types of biases will be analyzed in this paper.

We focus on a class of rather simple and homogeneous life insurance policies. These products, called deferred annuities, consist of a single or periodic premium paid to the insurer, followed by a payment at maturity to the policyholder. The pay-out of these so-called deferred annuities is either guaranteed, or depends on the value of an underlying investment portfolio (i.e. unit linked). The size of the market for deferred annuities is substantial. Between 1997 and 2003, total annual premium income for these products is around 1.6 billion euros on average for the Netherlands.

For the purposes of this analysis, we created a unique dataset linking consumer survey data on product choice and consumer characteristics with data on quotations from insurance firms. We will analyze three decisions that consumers will have to make in order to buy this type of life insurance. The first decision concerns whether or not to use a financial advisor. The second choice is related to the type of insurance policy, whereas the third concerns the choice of 
insurance company. In particular the latter two choices will allow us to analyze the two types of bias mentioned above.

The paper is structured as follows. The next section summarizes the literature on financial advice and commission bias. The dataset underlying our analyses is described in section 3 . Section 4 presents our analysis of the choice of product type, while section 5 studies the choice of insurance company and the associated pay-out. Section 6 concludes.

\section{$2 \quad$ Literature survey}

\section{$2.1 \quad$ Theoretical literature}

Consumers contemplating the purchase of a financial product often face a dilemma. On the one hand, the infrequency of the individual purchase of financial products, the perceived complexity of such products and the high financial stakes all suggest that it might be wise to consult a financial advisor. On the other hand, there is a risk that the advisor will come up with a product that maximizes his own welfare, possibly to the detriment of the consumer. Thus, the advisorconsumer relationship has the properties of a principal-agent problem. The consumer (the principal) delegates the search for the best financial product to the advisor (the agent), but the true effort of the latter can only be observed by the former against significant costs.

What is the optimal contract in this setting? The theoretical literature on general principal-agent problems (not specifically related to settings with experts offering advice) finds that the remuneration of the agent should be based on the realized outcome, with the possibility that the agent will have to pay a fee to the principal in case of a low output realization (see Schoonbeek and Kooreman, 2005). However, this requires that the output is verifiable to the principal expost. In the case of financial products, long lags between advice and realization and the complexity of the product make this a dubious assumption. 
The question about what is the optimal contract in this type of principal-agent setting also pertains to the mode of payment, viz. fee-based, where the customer pays a - say - hourly fee to the advisor, versus commission-based payment, where the advisor receives a commission from the bank of insurance firm. Gravelle (1994) shows that neither mode of payment solves the asymmetric information problem: in both cases consumers will be exploited. However, he also shows that the welfare loss to consumers will be smaller in a fee-based system than in a commission based system. The reason (in Gravelle's model) is that in a fee based system, consumers' advice and financial products are priced separately, while in a commission based system the two are bundled, reducing consumer choice. This result is due to the assumption in Gravelle's model that in a commission-based system, consumers only become informed if they buy a product. In reality, consumers may shop around in a commission-based system, and obtain free advice before making their choice. In that case, consumers may even be better off than under a fee-based system.

The analyses above abstract from one potential disadvantage of commission-based advice. In a commission-based system, there may be a risk of commission bias, where the advisor tends to recommend those products which yield the highest commissions. Recent theoretical research, however, demonstrates that commission bias need not always be detrimental to consumers (see Bentz, 2001). Borrowing ideas from the economics of advertising, Bentz points out that insurance companies that offer higher commission rates may be signalling that their products are of better quality than those of their competitors. He also shows that this will only work if, after having purchased the product, buyers find out the true quality of the product, after which they decide to continue to purchase the product or surrender the product early. It is questionable whether this is sufficiently applicable in the case of deferred annuities. Only at the pay-out date buyers will find out the true quality, but the decision to continue or surrender is not relevant then. After all, deferred annuities are meant as long term saving products that are typically bought only once during one's lifetime. In other words, buyers only find out the true quality when it is already too late. 
In conclusion, whilst theory suggests that asymmetric information between consumers and financial advisors gives rise to a principal-agent problem, it offers no clear guidance on the optimal contract. Compared to fee-based advice, commission-based advice may lower search costs for consumers, but it also entails the risk of commission bias.

\subsection{Empirical work}

In this section we summarize the (sparse) empirical literature on a possible bias in financial advice as a consequence of the incentives facing financial advisors. Many consumers invoke the services of financial advisors before choosing their product or provider. According to a recent survey by Forrester Research (a consultancy), 53\% of European consumers use financial advisors. This survey also indicated that most consumers believe that they do not pay for advice and that they are unwilling to pay for it. ${ }^{1}$

\section{UK private pensions}

The large-scale introduction of private pensions in the UK provides a much-discussed case of bad financial advice with disastrous consequences. In 1988, the UK government made it possible for workers to opt-out of their occupational pension scheme. By 1995, some 5 million workers had indeed opted out. Many of these workers were badly informed by financial advisers and as a result made severe errors in their pensions savings. According to Davis (2004), “500,000 individuals were persuaded by commission-driven salesmen to leave occupational funds, of which $90 \%$ received inappropriate advice (owing to high transfer costs and no employer contribution). The response has been massive fines on insurance companies and tightening of regulations on selling. This issue continues to affect confidence in personal pensions, compounded by comparable concerns over misselling of endowment insurance policies to back mortgage loans for house purchase.” (Davis, 2004, p. 16). In 1997, the government started a large-scale program aimed at compensating the victims. Estimates of the costs of this programme amount to 5-25 billion pounds.

\footnotetext{
${ }^{1} \mathrm{Http}: / /$ www.forrester.com/Research/Document/Excerpt/0,7211,35259,00.html, accessed December 19, 2005.
} 


\section{Financial products in the UK}

In an analysis of commission bias in the markets for financial products in the UK, Charles River Associates (in a study commissioned by the Financial Services Authority (2002)), presents two types of evidence. The first type of evidence consists of an econometric analysis of the relationship between market share and the level of commission paid to advisors. Here, the hypothesis to be tested is that higher commissions lead to higher market share. This would be interpreted as evidence in favour of commission bias. The results of this analysis indicate that for most financial products (20 out of 24$)$, the null hypothesis of no relationship was not rejected. However, for two important products, pension annuities and unit-linked endowments (a kind of life insurance to pay-off the mortgage), clear statistical evidence of commission bias was detected. In the case of annuities, the effect was quite small, with a $10 \%$ increase in commission rates relative to competitors' rates leading to a $6 \%$ increase in market share. However, in the case of unit-linked endowments, the corresponding effect was much larger: in this case a $10 \%$ increase in commissions is predicted to result in a 4.5 percentage point larger share of the market for these products.

The second type of evidence presented by Charles River Associates consists of a 'mystery shopping' exercise. 'Shoppers' were sent to 250 financial advisors with instructions to get advice on either a lump sum inheritance to invest, or a private pension scheme. This yielded 179 complete observations (the remaining 61 could not be completed 'in a timely fashion')

Advisors included both tied advisors (with financial ties to one company) and independent financial advisers (IFAs). The advice received was then compared to what would constitute the best advice (according to a group of advisors consulted by the researchers). In the first case (an inheritance to invest) these advisors agreed that an ISA (a tax-favoured individual saving account) plus cash savings account would be optimal, in the second case (pension) the advisers agreed that a stakeholder pension would be optimal. The outcomes of the mystery shopping exercise showed that in the case of the inheritance to invest, 1 in 5 advisers failed to recommend the right product. Perhaps surprisingly, the wrong advice came predominantly from IFAs, not 
from tied advisers. In 9 out of 72 cases, the researchers concluded that wrong advice was given. In these cases, the products that were recommended on average carried much higher commissions $(6.5 \%$ instead of $2.8 \%)$. Although no statistical test is performed, this suggests commission bias. However, no relationship was found between provider choice and the level commission.

Turning to the pension case, tied advisors again performed better than the IFA, with the former in over half of all cases advising a stakeholder pension and the latter in less than $25 \%$ of all cases. In only 5 out of 95 cases the wrong advice may have been due to commission bias, as in the remaining cases the level of commission for the two types of products was almost the same.

\section{Mortgages in the Netherlands}

Bruggert et al. (2004) present an empirical analysis on commission bias in the advice for mortgages in The Netherlands. They use data from a survey among 418 households who had recently taken out a mortgage. Of these 418 households, 241 consulted an advisor while the remaining 177 took the mortgage directly from their bank or other mortgage provider. The main finding of the study is that households who consult an advisor tend to purchase a complex type of mortgage more frequently, in particular equity-based mortgages (with these mortgages, monthly premiums are invested in equity funds; there is no guaranteed capital). The difference is large: $36 \%$ of those who consult one or more advisors had purchased an equity based mortgage, compared to only $17 \%$ of those who did not consult an advisor. Those who did not consult an advisor tended to buy much more frequently mortgages without redemption (29\% compared to $18 \%$ ). Commission rates on mortgages without redemption were much lower than on mortgages with redemption ( $0.5-1 \%$ compared to $2 \%)$.

Bruggert et al. also assessed whether respondents had obtained the lowest interest rate available in the market (given their product choice). They assessed this separately for the group that did use one or more advisors and the group that did not use any advice. The standard errors from this exercise imply that the null hypothesis that both groups received the lowest interest rate 
available cannot be rejected. They also looked at the fit between the type of mortgage the household "should" have taken (on the basis of stated preference) and the actual mortgage type chosen. This was achieved by feeding answers of respondent about the desired product type into an internet-site that gives financial advice. They found that there is no difference in fit between those who do and those who do not consult a financial advisor. However, after removing five cases from their dataset in which a worse fit goes hand in hand with a lower interest rate, they did find that those who used an advisor pay on average significantly higher interest rates.

In summary, the few existing empirical studies do point in the direction of commission bias, but the evidence is not overwhelming. Further, existing empirical research does not always clarify whether consumers were actually worse off as a result of the biased advice. Since the analysis in the present study allows us to determine quite unambiguously which firm had the best offer given the characteristics of the consumers, we will be able to determine the impact of advice on the quality of the outcome of the choice process.

\section{$3 \quad$ Data}

We use two types of data to perform our empirical analyses. To analyse what choices people made and why they made these choices, we make use of a consumer survey by CentERdata, a data collection firm linked to Tilburg University. To evaluate how well people have selected their insurance company, we obtained data on insurers' quotations from the Consumentenbond (the largest Dutch consumer organization) and MoneyView (a private firm selling financial information). Both datasets will be further described below.

\section{Consumer survey}

The consumer survey was conducted in September 2004, by means of an on-line questionnaire. ${ }^{2}$ Within its panel, CentERdata had previously collected data on the purchase of life insurances.

\footnotetext{
${ }^{2}$ CentERdata is an institute related to the University of Tilburg, and specialised in acquiring data through the Internet by using a panel of about 2000 persons. The panel is representative of the population in the Netherlands, with regard to sex, age, level of education, religion, geographical residence, marital state and number of persons per household (see http://www.uvt.nl/centerdata/nl/). 
These data contain information on number and type of policies purchased, date of purchase and the insurance company from which the insurance policy was purchased. However, these data did not identify through which distribution channel a particular product was purchased, or what type of information was used by the consumer before purchasing the insurance policy. Our survey was therefore aimed at unveiling through which distribution channel these insurance products were purchased and what type of information was available and used by the consumer. Thus, our questionnaire basically contains questions about how and why people bought their policies.

In total, 368 respondents from 351 different households completed the questionnaire. They purchased in total 562 products. Respondents are rather evenly spread over the two types of products (unit-linked and guaranteed pay-out) and distribution channel (insurance advisor and a direct writer).

The number of annual purchases is not constant over time. The period over which the majority of products included in the survey were purchased ranges roughly from 1985 until 2001. Figure 1 shows a steady rise in the number of products purchased, starting around 1995, with a peak around 2000, after which the number of products purchased shows a steep decline. This decline is most certainly due to the stricter tax exemption rules that applied to these policies since 2001 .

\section{$<$ INSERT FIGURE 1 HERE>}

In the period 1995-2001, much more unit-linked policies were sold, as compared to the number of policies with a guaranteed pay-out. This largely coincides with a booming stock market, and possibly suggests a link between the performance of stock markets and the preference for unitlinked product. 
In table 1 a number of survey statistics for the entire dataset is given.

\section{$<$ INSERT TABLE 1 HERE $>$}

\section{Quotation database}

Within the CentERdata panel, a number of respondents indicated that they had bought a life insurance policy with a guaranteed pay-out. For these respondents we know which insurance company they have selected, the premiums they have paid, the year of purchase and other personal characteristics (gender, age, et cetera.). What we don't know from these survey data is the set of choices these respondents were facing at the time of purchase.

To establish the relevant choice sets for these respondents, we obtained data on quotations by insurance companies from the Consumentenbond and MoneyView. Each quote is based on the age of a (fictitious) applicant, gender, the term and restitution type of the policy, and the amount of the single or regular premium. By restitution type we mean whether or not the insurance pays out in case the holder dies before the end of the term. As the vast majority chooses a policy that is payable if the holder dies within the term, we only include this type of policies in our quotation database. ${ }^{3}$ After excluding policies that are not payable in case of death, data on 2253 quotations remain. These data cover 46 insurance companies that together capture virtually the whole market for life insurances, for the period 1996 until 2003. The remaining quotes can be represented in 130 different tables, where each table contains quotes from different insurers, but with identical policy conditions. ${ }^{4}$ Hence, on average around 17 insurance companies are present in each table.

\footnotetext{
${ }^{3}$ The data from the consumer survey do not allow us to determine what restitution type of policy the households have actually bought. However, the empirical results below are robust to the assumption we make here. I.e., assuming that all respondents bought a policy that does not pay out in case of premature death does not alter the empirical results below. ${ }^{4}$ Only some minor differences remain in the percentage of the capital paid out in case the policy holder dies. The effects of these differences on the relative pay-out of the policies are negligible.
} 


\section{$4 \quad$ Financial advice and the choice of product type}

\subsection{Introduction}

In this section we analyze the effect of financial advice on the choice of type of product. We will assess whether the relation between stated risk aversion and the choice of safe versus risky products is affected by financial advice. The choices by consumers who purchase their insurance product through an insurance advisor may differ from those by consumers who purchase directly from an insurer. Consumers might have difficulties searching for products, they might find it difficult to compare various products, and they might have a hard time judging which product fits their characteristics best. Insurance advisors play an important role in overcoming these information asymmetries and in lowering search costs. An insurance advisor should be able to judge what a consumer needs, to classify a product with respect to these needs, and to search for and compare various products. We therefore expect the effect of consumer characteristics on product choice to be more pronounced for consumers who purchase their policies through an insurance advisor. The hypothesis we will test is that financial advisors help consumers in mapping their preferences with respect to risk bearing into their choice of financial product.

Further, we analyse what factors determine the consumers' choice of distribution channel. Knowing these determinants might help policy makers to design effective strategies to influence consumer behaviour and thereby intensify competition. For example, a policy issue which has received some attention in the Netherlands is to what extent insurance advisors should disclose to consumers the way in which they are remunerated and the level of remuneration. If knowledge by consumers of an insurance advisors' remuneration influences either the distribution channel or the type of product chosen, transparency with respect to remuneration can be an effective policy instrument to influence consumer behaviour. 


\subsection{Method}

There are two types of insurance policies in our data set: policies with a guaranteed pay-out and unit-linked products. In the latter case the pay-out is determined by an underlying investment portfolio. This implies that the pay-out can only be predicted on average. In the former case, the consumer knows exactly what she will receive at the end of the duration of the insurance policy. This leads to a natural classification of policies in two types: risky and safe, where a unit-linked product is called 'risky', whereas products with a guaranteed pay-out are labelled 'safe'. In this section, we study the influence of the use of an insurance advisor on the type of product a consumer chooses to purchase.

We assume that consumers make two consecutive choices. They first choose how to purchase their deferred annuity (directly from an insurer or through a financial advisor) and then choose what product (safe or risky) to purchase. Such a two-step choice process differs from a one-step choice between several alternatives with characteristics that can be grouped together, such as the choice between travel mode (plain vs various modes over land), migration, or where to go skiing. ${ }^{5}$ Our analysis more resembles the bivariate switching regressions used to determine, e.g., what factors influence wage levels, allowing for selection effects due to the choice whether to work or not (see, e.g., Kimhi 1999).

If selection effects are present in our analysis, estimating the above two binary choices independently results in selection bias. Selection bias may occur, e.g., if there are unobserved characteristics that influence both the choice between purchasing through an insurance advisor and directly from an insurer as well as the choice between safe and risky products. We therefore first tested whether selection effects are present by means of a switching regression model. ${ }^{6}$ As

\footnotetext{
${ }^{5}$ For example, when modelling choice and switching behaviour between Scottish ski centres, ski resorts can be grouped according to geographic location. People are assumed to first choose a location, and then a resort. See Riddington et al. (2000).

${ }^{6}$ Such a model thus describes both how consumers choose between direct purchase and using an insurance advisor, as well as the choice between safe and risky products, while allowing the error terms of these two equations (accounting for unobserved, randomly distributed characteristics) to be correlated.
} 
the results of this model indicate that selection effects are absent ${ }^{7}$, we estimated the choice of distribution channel and the choice of product type independently.

To determine the factors influencing choice of distribution channel we will hence estimate a simple binary choice model. To analyse the impact of using an insurance advisor, we estimate a binary choice model (describing the relation between a consumer's choice and a consumer's characteristics) twice: once for the group of respondents purchasing through an insurance advisor, and once for the group of respondents purchasing directly from an insurer. If the resulting two sets of coefficients differ significantly, using an insurance advisor influences consumer product choice. Below, we discuss separately for both choices what explanatory variables we include in the regression.

\section{Choice of product type}

A consumer's choice between a safe and a risky product will depend on the utility she derives from purchase of one type of product relative to the other type. The utility consumers derive from purchasing a particular type of insurance policy depends on the characteristics of this product (in this case it's risk level), the tastes of consumers with respect to this characteristic and the costs incurred while trying to match preferences and product characteristics (search costs). The relevant explanatory variables are therefore a consumer's risk preferences, factors that influence a consumer's risk preference and factors that influence consumers' search costs.

People who are relatively risk-averse will prefer safe products to risky products. On average, risk-averse consumers should purchase more products with a guaranteed pay-out, whereas consumers who are risk-seekers should purchase more unit-linked products. Thus, it is reasonable to assume that a consumer's risk appetite influences his or her choice between unitlinked products and products with a guaranteed pay-out. We use stated risk aversion as a proxy for respondents' risk preferences. ${ }^{8}$

\footnotetext{
${ }^{7}$ More formally: there was no significant correlation between the error terms.

${ }^{8}$ People were asked to what extent (on a scale from 1 to 7 ) they would agree to the following proposition: 'I consider it to be more important to invest safely and receive a guaranteed pay-out than to take risk in order to receive the highest possible 
Income might be another factor that influences a consumer's risk preference. People with a higher income will be able to take on more risky investments with less adverse consequences for their personal finances. Therefore, a given level of risk aversion might relate differently to product choice for people with a high level of income than for people with low incomes. Because the effect of additional income will presumably be less strong for higher levels of income, we take the natural logarithm of income as the appropriate explanatory variable.

In addition, age might affect the choice between a safe or risky product. Elderly people have a lower remaining life expectancy. Therefore, elderly people will have less time to average out fluctuations in level of the stock markets. This means that the risk involved in purchasing a unit-linked product is higher. We might therefore expect elderly people on average to buy less unit-linked products.

The average consumer's preference for risky products might shift over time. To capture potential shifts in consumer preference, we make use of a year dummy. This dummy allows for changing (average) consumer preference over time. For example, it allows distinguishing between the period when consumers expected the stock market to boom (approximately between 1995 and 2000), during which respondents can be expected to have more appetite for risky investments, and the years before and after this period.

Apart from the level of risk aversion, an important candidate that might influence a consumer's search cost, and therefore the type of product chosen, is a consumer's financial expertise. Respondents with a higher level of financial expertise might be more able to judge how risky a particular product is. Therefore, the higher the level of a consumer's financial expertise, the better he might be able to match risk aversion with his or her product choice. Because this

yield'. A potential problem with this procedure might be that consumers rationalise their choices ex-post: the questions was asked after respondents had already purchased the insurance policy. 
reasoning is only valid for people who indeed have a high level of expertise, it is the revealed level of expertise rather than the stated level of knowledge that is relevant. ${ }^{9}$

Revealed financial expertise is approximated by a dummy that accounts for correctly answering two questions about the (general) conditions of their policy. These questions were about what would happen when the policy expires. The first one was about what the respondent could do with his pay-out. Five options, including "I don't know" were presented. The second question was as follows: do you have to buy your annuity from the same company you bought your life insurance policy from?

\section{Choice of distribution channel}

Whether a consumer uses an intermediary, depends on the additional utility she derives from purchasing the product through an insurance advisor, instead of searching for the product that best matches her preferences herself. The use of an insurance advisor reduces her search costs. If the search costs outweigh the expected extra costs of 'hiring' an advisor she will use an advisor.

What factors influence a consumer's choice between direct purchase and using an insurance advisor? Knowledge by the consumer of the way in which insurance advisors are remunerated will influence the expected cost of hiring an advisor, and might therefore influence the choice of distribution channel. Possibly, consumers will be more inclined to purchase products through direct writing if they know insurance advisors receive a considerable amount of money if they sell a product. We measure the level of remuneration awareness by asking consumers whether they know in what way an insurance advisor is remunerated. If the question is answered correctly, remuneration awareness is set to 'high'; otherwise it is set to 'low'.

A second variable that might influence the choice of distribution channel is a consumer's stated knowledge of financial products. Consumers who claim to have a high level of financial

\footnotetext{
${ }^{9}$ Also, this reasoning implies that revealed expertise should enter the model as a cross-term with risk-aversion. We expect no direct effect of level of financial expertise on product choice.

14
} 
expertise may think they can compare financial product themselves (i.e., lower perceived search costs), without the help of an insurance advisor. Consumers with a high stated level of financial expertise might therefore be more inclined to purchase insurance products directly. ${ }^{10}$

A third variable influencing the use of distribution channel might be age (at the time of purchase of the product). Elderly people might be less able to compare complex financial products. Also, the Internet is an important tool in searching for a financial product. Elderly people might be less inclined to use Internet, especially for such purposes. We expect therefore that older people make more use of advisors.

The higher one's income, the bigger the opportunity costs of searching for a financial product. People with a higher level of income might be less willing to spend leisure time in searching for products themselves. We therefore expect that income will positively affect the choice for an insurance advisor. Because the effect of additional income will presumably be less strong for high levels of income, we take the natural logarithm of income as the appropriate explanatory variable.

The level of education could be important as well. Respondents with a high level of education may be more able to search for the best offer than people with a low level of education. We distinguish between respondent with a 'low' and a 'high' (i.e., college) level of education. Finally, gender might influence the use of distribution channel. For example, men might be more interested in financial products and might therefore be willing to invest more time in searching for an offer from a direct writer.

\subsection{Results}

The results of the switching regression model indicate that there are no significant selection effects (i.e., no significantly correlated error terms). We therefore estimated three separate

\footnotetext{
${ }^{10}$ We measure a respondents stated level of knowledge by asking whether she considers herself an expert in financial matters on a scale of 1 to 4 . Respondents who answer 3 or higher are classified as having a 'high' stated level of expertise.
} 
equations determining respectively the choice of the distribution channel and, for each distribution channel, the choice of risky versus safe product.

We have restricted the sample by including only the first policy respondents bought. As respondents have answered the questionnaire for each product separately, serial correlation could exist for respondents that bought more than one policy. Different observations may then no longer be independent, as they correspond to one single respondent. ${ }^{11}$

\subsubsection{Choice of distribution channel}

To evaluate which factors influence choice of distribution channel, we estimated the following binomial choice equation, where we take the distribution function to be standard logistic, resulting in a logit model.

$I B_{i}^{*}=x_{i} \beta+\varepsilon_{i}, \varepsilon_{i} \sim$ I.I.D.

$I B_{i}=0 \quad$ if $I B_{i}^{*} \leq 0$

(Error! Style not defined..1)

$I B_{i}=1$ if $I B_{i}^{*}>0$

Here, $I B^{*}$ is unobserved; only the dichotomous choice whether or not to use an insurance broker $(I B=1$ respectively $I B=0)$ is observed. To identify which parameters influence a consumer's choice of distribution channel, we estimated the probability of purchasing an insurance product through an insurance advisor as a function of transparency, stated expertise, age, income, educational level and gender (denoted by the vector $x_{i}$ ) by maximizing the likelihood of the observed choices. The results are presented in table 2.

$<$ INSERT TABLE 2 HERE $>$

\footnotetext{
${ }^{11}$ We have checked for robustness against selecting the observation included in the analysis. Choosing the second product for those who purchased more than one product does not influence our results. Also, the regression results are robust against including all data points and estimating without correcting for multiple products per respondent.
}

16 
The results in table 2 show that age, education level and commission awareness are significant in determining which distribution channel is chosen. ${ }^{12}$ First, the higher someone's age, the less likely it is that this person will buy products from an insurance advisor. This result contradicts our hypothesis that old people would prefer to use an advisor. Second, and in line with our hypothesis, the higher the education level of consumers, the lower the probability that he or she will buy insurance products through an insurance advisor. Finally, the more consumers know about remuneration (the more commission aware they are), the more probable it is that they will buy products directly from an insurer instead of through an insurance advisor. Also this result is in line with our hypothesis.

The effect of commission awareness is the most important effect of these three significant variables. If people are aware they actually pay for the advice they receive, they will search for an insurance product themselves more often. If consumers know how insurance advisors were remunerated, the probability of purchasing directly from an insurer increases with no less than 40 percentage points (for an average consumer).

\section{Diagnostics}

We have performed several specification tests to check for heteroscedasticity and nonnormality. A Breusch-Pagan test does not reject the null-hypothesis of no heteroscedasticity, as the Breusch-Pagan test statistic of 6.48 is below the $95 \%$-critical value of the Chi-squared distribution with 6 degrees of freedom (i.e. 12.59). Also, the null-hypothesis of no nonnormality cannot be rejected by a Jarque-Bera test at a $5 \%$ significance level. The value of the test statistic is only 2.75 , which is well below the critical value Chi-squared distribution with two degrees of freedom (i.e. 5.99). In addition, co-linearity is not an issue because there is no strong correlation between our explanatory variables. The strongest correlation we observed (between gender and income) is only -0.48 .

\footnotetext{
${ }^{12}$ Taking into account other variables such as revealed expertise, number of products purchased or year dummy's for the period 1991-2001 does not influence these results. The year dummy's for 1996, 1997, 1998 and 2000 are significant and indicate an increased likelihood of purchasing through an insurance advisor. In addition, a Lagrange Multiplier test indicated there was no heteroscedasticity, except marginally in the variable 'education level'. However, a Wald test indicates that there is no heteroscedasticity in 'education level'.
} 
To evaluate the choice of product type, the following logit model has been estimated separately for consumers purchasing insurance products directly from an insurer and consumers purchasing insurance products through an insurance advisor:

$$
\begin{aligned}
& P_{0 i}^{*}=x_{i}^{\prime} \beta_{0}+\varepsilon_{0 i} \text { if } I B_{i}=0, \varepsilon_{0 i} \sim \text { I.I.D. } \\
& P_{1 i}^{*}=x_{i}^{\prime} \beta_{1}+\varepsilon_{1 i} \text { if } I B_{i}=1, \varepsilon_{1 i} \sim \text { I.I.D. } \\
& P_{i}=0 \quad \text { if } P_{0,1 i}^{*} \leq 0 \\
& P_{i}=1 \quad \text { if } P_{0,1 i}^{*}>0
\end{aligned}
$$

(Error! Style not defined..2)

As in (4.1), only the observed choices of choosing a safe policy $(P=1)$ or risky policy $(P=0)$ are observed. The vector $x_{i}^{\prime}$ contains the following explanatory variables: risk aversion, income, age, the dummy variable hype, and aversion crossed with revealed expertise. As mentioned, revealed expertise enters the equation crossed with aversion because it should have no direct influence on product choice, but could result in a stronger effect of aversion on product choice. The maximum likelihood estimates are presented below.

$<$ INSERT TABLE 3 HERE >

For consumers purchasing through the direct channel, there are two variables that have a significant influence on products choice: risk aversion and the year dummy variable. The estimation results suggest that for consumers purchasing insurance products directly from an insurer, risk aversion plays an important role in the choice consumers make. The sign of the coefficient for risk aversion implies that consumers with a higher level of risk aversion are indeed more likely to buy insurance products with a guaranteed pay-out. This confirms that people with a high level of stated risk aversion indeed prefer to purchase less risky products than people with a low level of stated risk aversion, giving confidence in the use of the stated 
risk aversion as a measure of revealed risk aversion. ${ }^{13}$ The other variable that is significantly related to consumer choice is the year dummy. The sign of the coefficient for this dummy implies that in the period 1995-2001, when stock markets were booming, people were more likely to buy unit linked products. ${ }^{14}$

For consumers purchasing products through an insurance advisor, only the year dummy is significant. The risk aversion of consumers purchasing through an insurance advisor is not significant in determining which type of product they purchase. ${ }^{15}$

\section{Diagnostics}

Again we performed a number of specification checks. A Breusch-Pagan test does not reject the null-hypthesis of no heteroscedasticity. The test statistics are, respectively, equal to 5.46 and 1.65 , and do not exceed the $95 \%$-critical value of the Chi-squared distribution with 5 degrees of freedom (i.e. 11.07). Further, the null-hypothesis of no non-normality cannot be rejected by a Jarque-Bera test at a $10 \%$ significance level in the case of purchase through an advisor and at a $5 \%$ level in the case of direct purchase. The test statistics for this test are, respectively, 7.04 and 0.146. Finally, co-linearity is not an issue because there is no strong correlation between our explanatory variables (in both samples no correlation coefficient exceeds 0.2 ).

\section{Interpretation}

The impact of risk aversion on product choice is different between direct purchasers and respondents using an advisor. We tested the null-hypothesis that the coefficients for risk-

\footnotetext{
${ }^{13}$ Another way in which one can gain confidence in stated risk aversion as a measure of revealed risk aversion is by relating it to variables like gender, age, income and education. If any of these is significant in explaining risk aversion, the relation should agree with naïve expectations. The result is that gross income, age and educational level are significantly related to risk aversion. Income is negatively related to risk aversion. The higher gross income, the lower risk aversion. Age and educational level are both positively related to risk aversion. The higher age or educational level, the higher the level risk of aversion. These dependencies are in line with what one would expect.

${ }^{14}$ For the entire sample, including respondents who purchased two or more insurance policies, we've also analysed product choice with a dummy for every year in the period 1990-2003. All dummies for 1990-1994 and 2002-2003 were not significant. A log-likelihood ratio test indicated that the restriction of all dummies from 1995-2001 being equal was not significant.

${ }^{15}$ We have checked our results for robustness by including variables for which there seems to be no obvious reason to include them, like gender, stated expertise and education level. These variables are not significant and including them does not influence our results.
} 
aversion are equal for the two distribution channels ${ }^{16}$, and found that this hypothesis is rejected at the $10 \%$ significance level. To interpret this different influence of risk aversion on consumer choice for the two distribution channels, we have tried to think of various possible scenarios that could explain why insurance advisors do not take into account a consumer's level of risk aversion when advising a certain type of product.

A first possibility is that the data we use do not represent the variables we think they represent. Suppose that in reality there is a relation between true risk aversion and product choice, but not between the stated level of risk aversion and product choice. On the basis of their expertise and a consumer's income, age etc. insurance advisors judge what the 'true' level of risk aversion is. There are two problems with this explanation. First, there is no significant relation between any of the other exogenous factors and product choice. This might imply that we have missed out on the most important variables explaining 'true' risk aversion. This seems implausible. Second, there is no significant relation at all between stated risk aversion and product choice. If we assume that true risk aversion does influence product choice, stated risk aversion and true risk aversion should not be related. Our results show there is a relation between stated risk aversion and type of product chosen for direct purchase, suggesting that a respondent's stated level of risk aversion indeed corresponds to his or her true level of risk aversion.

Therefore, a more probable explanation is that insurance advisors, on average, either ignore risk aversion, or treat all consumers as having the same level of risk aversion. On the basis of other variables, such as age, income and educational level, the insurance advisor then searches for the best product. However, again we note that none of the variables that might influence the type of product chosen are significant. This then leads to the question: on the basis of what factors do insurance advisors advise their clients a particular type of product?

\footnotetext{
${ }^{16}$ This was done by estimating model (4.2) for both subsamples taken together and using dummies for one group.

20
} 


\section{$5 \quad$ Financial advice and the choice of insurance company}

The previous section has dealt with the choice of product type. This section focuses on the choice of firm. In particular, we will analyze the effect of using financial advice on the pay-out per euro invested. This implies that we limit our sample to choices involving policies with a guaranteed pay-out. Only for these policies we can assess how well people have made their choices. We will do this by comparing the guaranteed pay-out of the policies that consumers actually purchased with the pay-out of the policies consumers could have purchased, given their individual characteristics and given the offers available in the year in which the purchase was made. Since the pay-out (per euro invested) is the only relevant criterion for this type of policies $^{17}$, it constitutes an unambiguous performance measure for the chosen life insurance.

\section{$5.1 \quad$ Method}

Virtually all insurers offer life insurance policies with a guaranteed pay-out, but, for a given individual, differences between insurance companies can be substantial. Let us consider a reallife example. In November 2000, the Dutch consumer organisation Consumentenbond has collected quotations for a single premium life insurance for a male, aged 45 , investing a single premium of 2804 euros for 20 years. In total, quotations were obtained from 22 different life insurers. The average pay-out equals 8179 euros. But the difference between the insurer with the highest pay-out and the lowest pay-out amounts to more than 3000 euro for identical policy conditions. As there is no relationship between the size and age of these 22 insurers on the one hand, and the quoted pay-out on the other, these large differences cannot be explained by differences in reputations. Moreover, all these insurance companies are supervised by the Dutch central bank. This prudential supervision explicitly aims to minimise the default risk of life insurance companies and, as such, protect their policy-holders.

\footnotetext{
${ }^{17}$ The default risk of the insurer might be relevant too. However, as we will discuss below, prudential supervision is aimed to minimize this risk for all active life insurers.
} 
Hence, the choice of insurance company could matter a lot. But how well do people actually make their choices? In order to answer this question we constructed a database that consists of the following pieces. For each individual of the CentERdata panel that bought a life insurance with a guaranteed pay-out, we know which insurance company he or she selected. Further, we constructed for each individual a choice set containing all insurance companies that the respondent could have chosen, including the pay-out that the respondent would get from these insurance companies. By comparing the pay-out of the company that was actually chosen with the pay-outs of the other life insurers, we can assess how well the actual choice of the respondent is, given his choice set.

Each choice set is constructed by linking one of the 130 quotation tables (which were described in section 3 ) to the individual policy for each respondent in our sample. ${ }^{18}$ As the conditions of the quotations are hardly ever exactly the same as the characteristics of the respondents' policies, we have to find the set of relevant quotations that is closest to the policy of the respondent. We have adopted the following rule to determine which table of quotations is most appropriate. We take the table of which the (absolute) differences between the conditions of the quotes and the conditions of the respondent's policy is minimal, taking into account the following order of conditions: year of quotation, gender, age, duration and premium. Thus, first we select tables on the basis of closest quotation year. Then, from the remaining set of tables we select the tables on closest gender, then on closest age, and finally on closest premium paid. ${ }^{19}$

After linking the table of relevant quotations to the policies of the respondents in our sample, we have the actual choice of policy the respondent has made and a table that consist of quotes from different companies based on conditions similar to the conditions of the respondent's policy. This enables us to assess how well the choice of the respondent actually was by comparing the (quoted) guaranteed payment of the selected insurance company with the guaranteed payments of the other companies. As mentioned before, from the consumers' point

\footnotetext{
${ }^{18}$ If respondents purchased a policy from a company of which no quotes are available at all, these respondents were obviously removed from the analysis.

${ }^{19}$ The choice of order for the last four variables is rather arbitrary. However, the results presented below are robust to the order of these conditions.
}

22 
of view, these payments are the only relevant product characteristic in which policies with guaranteed payments could differ between insurers. ${ }^{20}$ The policies are therefore directly comparable by looking at differences between these guaranteed pay-outs. The pay-outs can thus be used to benchmark the actual choices of the respondents.

The simplest way to do this is by looking at how much more money the respondent could have made if he had chosen the best quotation. However, different respondents have different policies. We therefore have to express the quality of the choice in relative terms in order to make fair comparisons between respondents. We propose a variable, labelled Pay-out Index $(P O I)$ to assess the quality of a given choice:

$P O I=\frac{\text { actual payout }}{\text { average payout }}-1$

(Error! Style not defined..1)

We thus evaluate the actual choice by the relative distance of the quoted pay-out of the chosen company to the mean pay-out in the relevant table of quotations. ${ }^{21}$ The figure below shows the histogram of $P O I$ for all available quotations. This histogram confirms that the differences within a choice set can be very large. For some policies, consumers could get a $32 \%$ higher pay-out than average. But we also observe quotations that offer a pay-out that is more than 40 $\%$ below average.

$<$ INSERT FIGURE 2 HERE $>$

\section{Explanatory variables}

What factors explain how well consumers make their choice of insurance company? We hypothesise the following determinants:

\footnotetext{
${ }^{20}$ In a very few cases, profit-sharing arrangements may lead to a higher pay-out ex post. Leaving out these observations did not alter the results presented below.

${ }^{21}$ In stead of comparing the actual pay-out to the mean pay-out, we have also used the maximum pay-out as the benchmark within a choice set. Again, the results are robust to this. We have chosen to use the mean as the benchmark, because it is more stable if, for some reason, a typical cheap or expensive insurance company is not quoted in a particular year.
} 
The use of an intermediary: intermediaries have the knowledge to support consumers to buy the best policy available. Although moral hazard and commission bias can negatively affect the effort and the quality of the advice, one might still expect that the expertise and experience of the intermediary suffices to obtain a better result.

Search intensity: consumers that are more active in searching are likely to find better policies. Obtaining information about the pay-out of deferred annuities requires some search effort. The optimal search intensity is at the level where marginal (expected) revenue of search equals marginal search costs. We do not know exactly the respondents' valuation of their (expected) revenue and search costs. However, the large differences that exist between comparable quotations leads us to expect that, at least for low levels of search intensity, marginal revenue exceeds marginal search cost.

Financial expertise: consumers with a better understanding of financial products (both stated and revealed) are expected to find better policies. A consumer with experience and expertise on financial products might, e.g., be well aware of the existence of prudential supervision. He or she is therefore likely to know that the pay-out of the annuity is the only relevant criterion to base his decision on (rather than, e.g., the insurer's reputation).

Education: highly educated people are expected to better understand and select the right policy. Also here we expect that respondents with a higher education level are better aware of the relevant differences between policies, and will therefore make better decisions.

We will estimate the impact of these variables on POI using the following explanatory variables. Search behaviour is represented by a variable labelled SOURCES. It counts the number of information sources the respondents had used during their decision making process. These six sources are: relevant newspaper articles, financial magazines, information published by the Consumentenbond (including tables of quotation), internet, brochures from insurance 
companies and financial software. Stated and revealed financial expertise, as well as education, are equal to the previous analysis.

\section{$5.2 \quad$ Results}

A priori, sample selection bias (between people that use an advisor and those who do not) cannot be ruled out. Perhaps there are unobserved characteristics that both explain why people use an advisor and how well people make their choice of insurer. Ignoring the possible existence of such unobserved characteristics can bias the results, because differences in $P O I$ may then be incorrectly attributed to the use of an advisor. In order to take this possible selection effect into account, we estimated the following switching regression model:

$$
\begin{aligned}
& I B_{i}^{*}=w_{i}^{\prime} \gamma+u_{i}, u_{i} \sim \text { N.I.D. }(0,1) \\
& I B_{i}=1 \text { if } I B_{i}^{*}>0 \\
& I B_{i}=0 \text { if } I B_{i}^{*} \leq 0 \\
& P O I_{0 i}=\alpha_{0}+x_{0 i}^{\prime} \beta_{0}+\varepsilon_{0 i} \text { if } I B_{i}=0 \\
& P O I_{1 i}=\alpha_{1}+x_{1 i}^{\prime} \beta_{1}+\varepsilon_{1 i} \text { if } I B_{i}=1
\end{aligned}
$$$$
\text { (Error! Style not defined..2) }
$$

Here, $\varepsilon_{0 i}$ and $\varepsilon_{1 i}$ are normally distributed, with variances $\sigma_{0}^{2}$ and $\sigma_{1}^{2}$ and covariances $\sigma_{02}$ and $\sigma_{12}$ with $u_{i}$. The vector $w$ contains the same independent variables as in model (4.1), and thus consists of remuneration awareness, stated expertise, age, log of income, education level and gender. The vectors $x_{0,1}$ include the number of information sources used, stated and revealed expertise, and the education level of the respondents.

We first tested the following three hypotheses (likelihood ratio's and critical values in brackets):

(1) $\beta_{0}=\beta_{1} \quad(\mathrm{LR}=5.12<9.49)$ 
(2) $\sigma_{0}^{2}=\sigma_{1}^{2} \quad(\mathrm{LR}=0.84<3.84)$

(3) $\sigma_{02}=\sigma_{12} \quad(\mathrm{LR}=1.97<3.84)$

The likelihood ratio tests of these hypothesis show that none of them can be rejected at the $5 \%$ significance level. The same applies to the imposition of all three restrictions simultaneously $(\mathrm{LR}=7.58<12.59)$. After imposing these three restrictions we obtain the following results.

\section{$<$ INSERT TABLE 4 HERE>}

Let us first focus on the intercepts for those who bought their policy through an insurance broker and those who did not. Respondents who purchased their policy directly from an insurer on average attain a pay-out that is around $7 \%$ above the mean pay-out. In contrast, people who bought their policy through an insurance broker get a pay-out that is more than $7 \%$ below the mean pay-out of available policies. Hence, respondents who bought their policy through an insurance broker receive a pay-out index that is more than 14 percentage points less than respondents who purchased their policy directly from an insurance company. This difference is statistically significant at the $97.5 \%$ significance level, based on a likelihood ratio test on the hypothesis that $\alpha_{0}=\alpha_{1}(\mathrm{LR}=6.10>5.02)$.

Further, we see that the other variables are not significant for both subgroups, except for stated expertise. Respondents who stated to have substantial financial knowledge indeed obtain a significantly higher pay-out, albeit only at the $93 \%$ significance level. With regard to the probability of using a financial advisor, the results are by and large the same as in the previous section.

The estimate for the covariance $\sigma_{02}\left(=\sigma_{12}\right)$ turns out to be significantly positive. Technically, this means that $u_{i}$ and $\varepsilon_{0,1 i}$ are positively correlated: there may be unobservable components that explain a higher pay-out for those who chose to use a financial advisor, and a lower pay-out 
for those who chose not to. Or, to put it less formally, respondents who chose to use a financial advisor despite their known characteristics (e.g. being aware of remuneration) obtain a higher pay-out than the average respondent. Bargaining skills or assertiveness could serve as examples of unobserved components that explain why some respondents use an insurance broker. Similarly, respondents who chose to not use a financial advisor despite their observed characteristics (e.g. being unaware of remuneration) obtain a lower pay-out than the average respondent. Perhaps these persons have been directly approached by one insurer, after which they simply accepted the offer without looking around for a better deal.

Note that the observed selection effect does not render the negative effect of using an insurance broker on the pay-out index insignificant. On average, the (absolute) selection effect is rather small: 0.44 percentage points in terms of the pay-out index, with a maximum value of less than one percentage point. ${ }^{22}$

But the most important result concerns the significant difference between the pay-out indexes. As mentioned, respondents who bought their policy through an insurance broker receive a payout index that is more than 14 percentage points less than respondents who purchased their policy directly from an insurance company. We can therefore conclude that (i) insurance brokers do not advice the best available policies for their customers, and (ii) consumers who buy through an insurance broker are worse off than those who do not.

\section{Diagnostics}

We first checked whether the error terms $\varepsilon_{0 i}$ and $\varepsilon_{1 i}$ are heteroskedastic. In particular, we looked at the effect of differences in the conditions of the quotations and the characteristics of the respondents' policies on the residuals. Although there is no reason to expect that the noise resulting from these differences will bias the result in one direction or the other, there may still

\footnotetext{
${ }^{22}$ For a given observation, the absolute selection effect is equal to the covariance between $u$ and $\varepsilon$ multiplied by the generalised residual of the probit model denoting the probability of using an advisor (see, e.g., Verbeek, 2004).
} 
be an effect on the size of the residuals. A Breusch-Pagan test, however, rejects the hypothesis of heteroskedastic error terms. ${ }^{23}$

Next, we checked if the error terms $\varepsilon_{0 i}$ and $\varepsilon_{1 i}$ can be assumed to be normally distributed. With values of 2.08 and 1.12, the test statistics of the Jarque-Bera test shows that this is indeed the case. ${ }^{24}$ Also, multicollinearity is not an issue, as there is no strong correlation among the explanatory variables in our sample. The strongest correlation we observe is -0.37 (between gender and log of income).

In the full sample, there are some respondents who bought more than one policy. There could therefore be some serial correlation in the residuals for these observations. Serial correlation could mean that the score of an individual on $P O I$ is better explained by an unobserved individual characteristic. In order to see whether serial correlation plays a role, we estimated model (5.2) on a sample in which we only include the first policy that respondents had bought. This restriction reduces the sample to 108 observations, but besides a small effect on the standard errors, this does not alter the results.

Finally, we investigated whether an alternative way of estimating the pay-out index would alter our results. Our original method (i.e. taking the closest table of quotations for respondents whose policies do not perfectly correspond to the quoted policies) constitutes a non-parametric method to estimate POI. The alternative would be to use a parametric method, by which we impute $P O I$ by estimating it for those respondents whose insurance company was not quoted in the year they bought the policy. As a robustness check, we have also applied this method to our data. The results are indeed robust with respect to using this different method. ${ }^{25}$

\footnotetext{
${ }^{23}$ Besides the differences in policy conditions, we also included the original regressors in this test. The test-statistics are 9.82 and 15.6, both below the $95 \%$ critical value of the Chi-squared distribution with 10 degrees of freedom (i.e. 18.31). ${ }^{24}$ Both are far below the $95 \%$ critical value of 5.99 resulting from the Chi-squared distribution with 2 degrees of freedom. ${ }^{25}$ A detailed description of this parametric method and its results can be obtained from the authors.
} 


\section{Interpretation}

The negative effect of using a financial advisor on the pay-out implies that, for the types of life insurances we analysed, advisors do not advise the best products for their clients. ${ }^{26}$ One possible explanation for this is that the advice of insurance brokers is biased towards insurers who pay a higher remuneration. In particular progressive remuneration schemes may give insurance brokers wrong incentives, not only from the perspective of their clients, but also for society as a whole. The reason is that this type of moral hazard in the market for financial advice may reduce competition between life insurers if consumers fail to buy the most competitive offer. In effect, this lowers the price elasticity for financial product under consideration.

\section{$6 \quad$ Conclusions}

The most important result of the empirical analyses in this paper is that financial advisors often fail to advise the best product to their clients. Advisors do not match the risk preferences of their clients with the type of product chosen. Furthermore, consumers who bought their life insurance policies through an insurance advisor received a significantly lower pay-out than the respondents that bought a policy directly from an insurer.

Several institutional factors may explain our results. First, due to asymmetric information, consumers can hardly know the quality of the advice in advance. There is no guarantee that the advice they get is truly independent. Policy could deal with this market failure by introducing certificates for independent advisors. These certificates should lay down certain minimum requirements, such as the number of different firms to be included in the comparison on which the advice is based, the absence of financial ties other than commission, the obligation to keep records of the advice process for at least a certain period etc. One could even go one step further by reserving the label 'independent' for advisors who are paid by consumers purely on the basis of fees per hour of advice.

\footnotetext{
${ }^{26}$ Assuming that consumers purchase the product their financial advisor advises.
} 
Remuneration schemes and bonuses may constitute a second institutional explanation for the weak performance of advisor. If consumers are unaware of these schemes, they cannot judge whether the advice they receive is biased or not. Our data unfortunately do not allow us to test this hypothesis. Such an analysis would require much more detailed information, including which advisor has sold the policy and what commission he would receive on each policy in his portfolio. Nevertheless, further improving the transparency of the remuneration that advisors get remains an interesting policy option. One way of achieving this is along the lines of the approach recently introduced in the UK, where advisors are obliged to present their customers with the market average of the costs of advice for similar products. In addition to improving transparency, policymakers may also regulate the contract terms between life insurance firms and financial advisors. By excluding certain types of contract conditions, it may be possible to better align the interests of consumers and advisors. The UK experience is once more relevant in this respect. So-called volume contracts are explicitly forbidden. In addition, financial advisors are not allowed to take out loans from banks or life insurance firms for which they sell financial products. Finally, presents, holiday trips, or bonuses from insurance firms to advisors are not allowed.

Besides these institutional factors, policy options dealing with consumers' bounded rationality may also enhance the decision making process in the market for financial products. Financial products are often regarded as "confusing” or even "boring” (FSA, 2004). Policy could, e.g., aim at improving consumer awareness of the need to shop around. One possibility is a policy experiment in which comparable information on financial products is made available to consumers for free. A second option is standardization of products. This has been attempted in the UK with the introduction of so-called stakeholder products. The stakeholder approach can be summarized as "standardization light" (since firms were still free to offer non-stakeholder products). There is at least one example from other markets were such a policy seems to work, namely the Norwegian energy market. 
Each of these policy options has potential costs in terms of implementation costs or administrative burden. Furthermore, the weak performance of advisors in the market for deferred annuities cannot be simply generalised to other financial products. However, it is important to realise that the incentive structure and (asymmetric) information problems might be very similar for mortgages, direct annuities, non-life insurances or private pension schemes. Our results indicate that potential benefits in consumer welfare already exist for rather simple financial products. Particularly the benefits of lighter forms of regulation may therefore greatly outweigh their implementation costs and, as such, lower the price of free advice. 


\section{References}

Bentz, A., (2001) Is Commission-Based Advice Always Bad Advice?, CMPO Working Paper, Series No. 01/42.

Bruggert, F., N. van der Lijn and A. Meijer (2004), Marktwerking op de markt voor hypothecaire kredietverlening, ECORYS-NEI.

Charles Rivers Associates (2002) Polarisation: research into the effect of commission based remuneration on advice, study for the Financial Services Authority, London.

Davis, E.P. (2004) Is there a Pension Crisis in the UK?, Pensions Institute Discussion Paper PI0401.

FSA (2004) Polarisation - Menu testing research, Research prepared for the Financial Services Authority by IFF Research Ltd and NOP Research Group.

Gravelle, H. (1994), Remunerating information providers: Commission versus fees in life insurance, Journal of Risk and Insurance, 61 (3), 42557.

Kimhi, A. (1999), Estimation of an endogenous switching regression model with discrete dependent variables: Monte-Carlo analysis and empirical application of three estimators, Empirical Economics, 24, 225-41.

Riddington, G., C. Sinclair, and N. Milne (2000) 'Modelling choice and switching behaviour between Scottish ski centres', Applied Economics, 32, 1011-18.

Schoonbeek, L., and P. Kooreman (2005), No cure, be paid: super-contingent fee contracts, Applied Economics Letters, 12, 549-51.

32 
Verbeek, M (2004) A Guide to Modern Econometrics, John Wiley \& Sons, Ltd, Chichester. 


\section{Acknowledgements}

We would like to thank Pierre Koning and an anonymous referee for useful comments and suggestions. 
Figure 1: Number of policies purchased by year and type

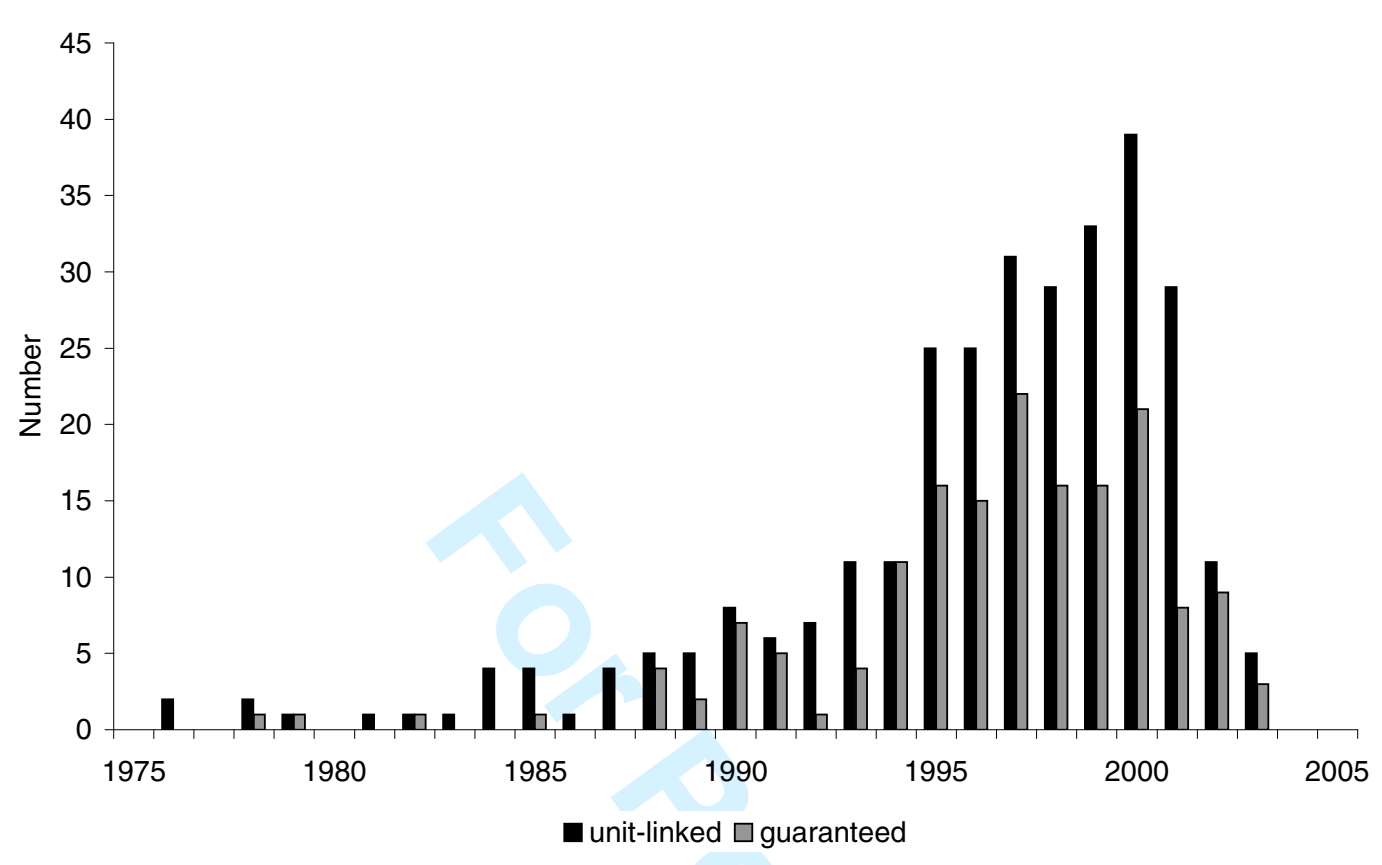




\begin{tabular}{lrr}
\hline Table $1 \quad$ Sample statistics by type of policy & & \\
& Guaranteed \\
Average age on purchase & 40 & 40 \\
Median monthly net income (in euros) & 1744 & 1618 \\
Percentage of respondents using an advisor & $58 \%$ & $58 \%$ \\
Percentage females & $27 \%$ & $36 \%$ \\
\hline
\end{tabular}


Table 2: Estimation results for logit model on choice of distribution channel

Parameter Estimate

T-value

Constant

1.157

0.45

Commission awareness

$-1.977$

$-6.53$

Stated expertise

$-0.346$

$-1.11$

Age

$-0.050$

$-3.37$

Log of income

0.323

1.01

Education level

$-0.658$

$-2.12$

Gender

0.273

0.74

Likelihood Ratio: 75.96

McFadden $R^{2}: 0.204$

Number of observations: 270 


\begin{tabular}{|c|c|c|c|c|}
\hline & Advisor & & Direct & \\
\hline & Parameter Estimate & T-value & Parameter Estimate & T-value \\
\hline Intercept & 4.327 & 1.52 & 1.47 & 0.48 \\
\hline Risk aversion & 0.010 & 0.09 & 0.28 & 2.02 \\
\hline Log of income & -0.483 & -1.44 & -0.28 & -0.79 \\
\hline Year dummy 1995-2001 & -1.430 & -3.39 & -1.47 & -3.42 \\
\hline Age & 0.014 & 0.71 & 0.01 & 0.06 \\
\hline Risk aversion $\times$ revealed expertise & -0.256 & -1.68 & -0.00 & -0.02 \\
\hline Likelihood Ratio & 16.03 & & 17.23 & \\
\hline McFadden $\mathrm{R}^{2}$ & 0.079 & & 0.103 & \\
\hline Number of observations & 146 & & 121 & \\
\hline
\end{tabular}




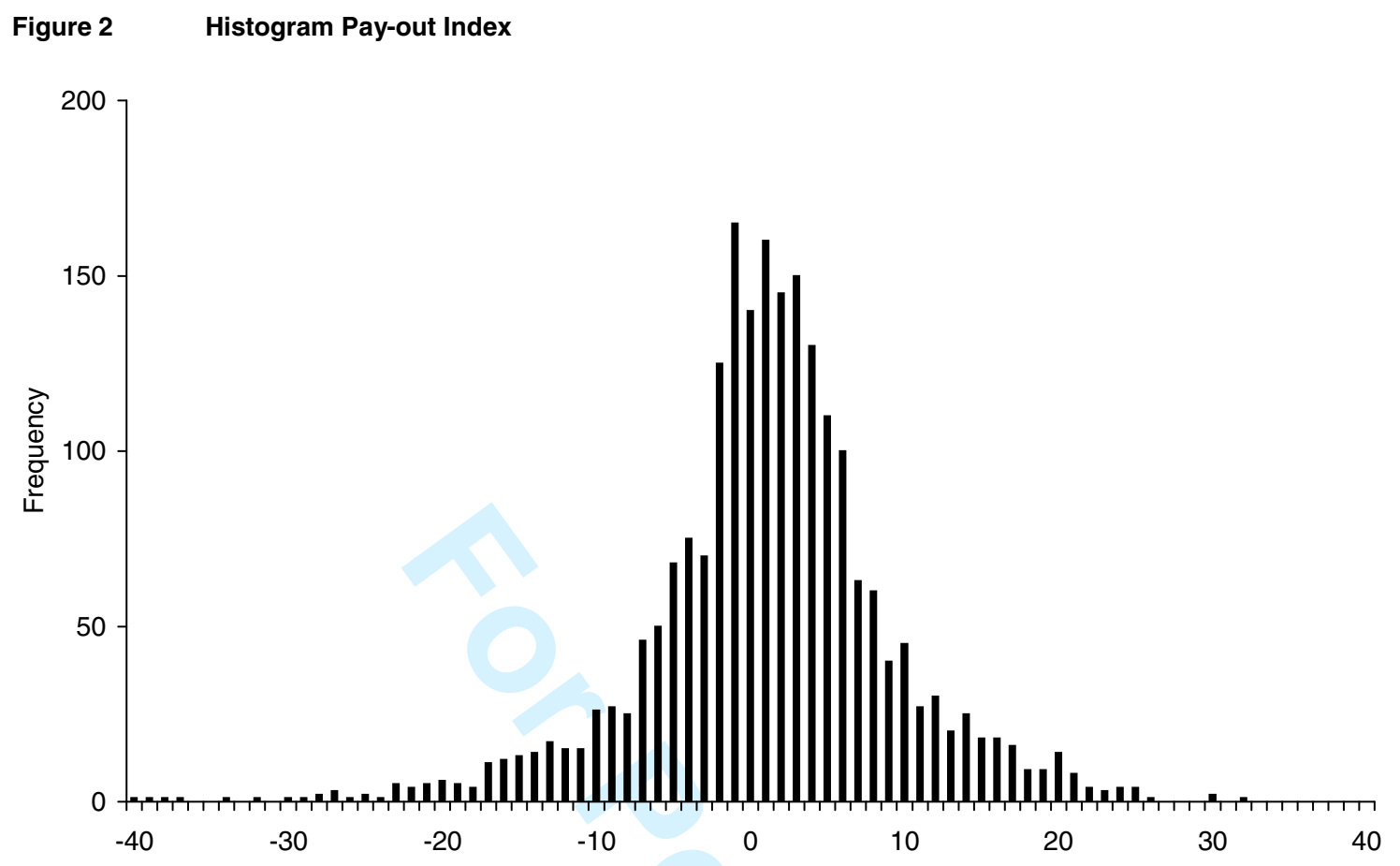




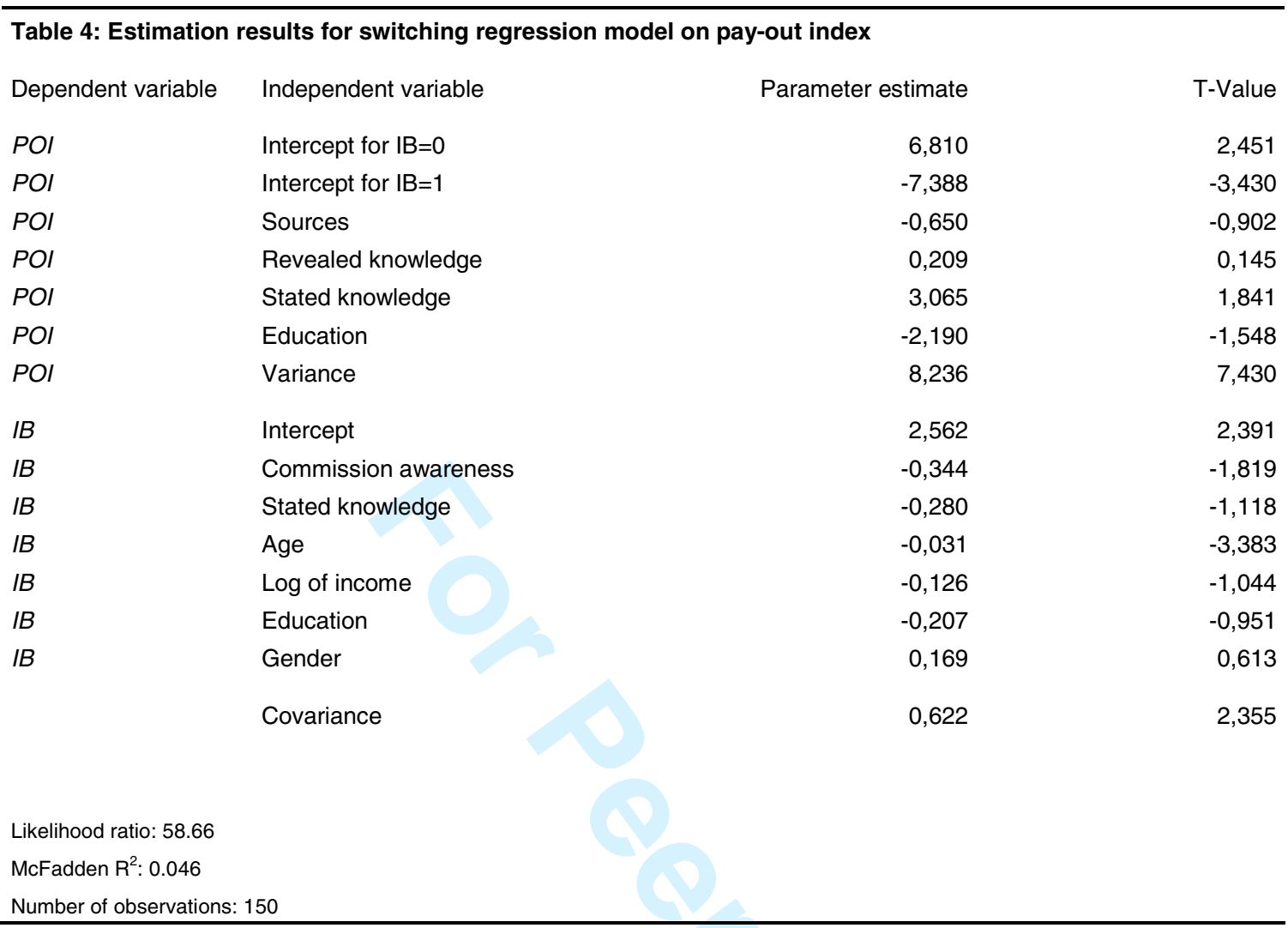

